\title{
Per-operative Advantages of Transanal Endorectal Pull Through (TERPT) Over Swenson's Procedure in the Surgical Treatment of Rectosigmoid Hirschsprung's Disease (HD)
}

\author{
ABU SALEH MD. WALIULLAH ${ }^{1}, \mathrm{SHOHELI} \mathrm{ALAM}^{1}, \mathrm{MA} \mathrm{AZIZ}^{2}, \mathrm{AR} \mathrm{KHAN}^{3}$
}

\begin{abstract}
:
Introduction: Popular Swenson's pull through (1948) is still the most commonly practiced 'Gold Standard' of operative treatment for rectosigmoid hirschsprung's disease (HD). But minimally invasive transanal endorectal pull through (TERPT) is now being increasingly practiced worldwide for its treatment in many centers. Here we are describing our comparative experience between TERPT and Swenson's pull through, at Dhaka Shishu Hospital to show the per-operative advantages of the former over the latter.

Materials and methods: It is a prospective study at Dhaka Shishu Hospital during January 2000 to December 2001 in 32 (age, body weight and resected Rectosigmoid length matched) biopsy confirmed patients of HD divided into two Groups: $G r$. A ( $n_{a}$ $=16)$ and Gr. $B\left(n_{b}=16\right)$ patients who underwent TERPT and Swenson's pull through respectively. Unpaired ' $t$ ' and $\chi^{2}$ (with Yate's correction) tests were used for statistical analysis whereas operative duration, volume of blood loss and transfusion requirements were used as parameters of the study.

Results: For study Group A (TERPT) - operative time, volume of blood loss and transfusion requirement were significantly lesser $(P<0.01, P<0.001$ and $P<0.001$ respectively) than the control Group $B$ (Swenson's procedure).

Conclusions: Through this small comparative study, TERPT was found to be more advantageous than the Swenson's pull through procedure in terms of operative duration, blood loss and transfusion requirement.
\end{abstract}

Key words: TERPT, Swenson's, Compare.

\section{Introduction}

Hirschsprung's Disease (HD) is recognized as the commonest cause of neonatal intestinal obstruction ${ }^{1}$. In 90\% cases, it involves the rectosigmoid region². Pull through operations devised by Swenson (1948), Duhamel (1956) and Soave (1964) have been regarded as the 'Gold Standards' of operative treatment for HD. Though each of these procedures has the advantages and disadvantages of its own, none of the procedures described for definitive treatment of HD could achieve perfect functional result ${ }^{3}$.

1. Resident, Department of Paediatric Surgery, Bangabandhu Sheikh Mujib Medical University, Dhaka

2. Associate Professor, Department of Paediatric Surgery, Bangladesh Institute of Child Health \& Dhaka Shishu Hospital, Dhaka

3. Professor, Department of Paediatric Surgery, Bangladesh Institute of Child Health \& Dhaka Shishu Hospital, Dhaka

Correspondence: Dr. Abusaleh Md. Waliullah
Swenson's procedure involves combination of abdominal and perineal approaches.

After laparotomy, mobilization and excision of the aganglionic colonic segment is carried out by extrarectal deep pelvic dissection in close proximity to both ureters, both vas deferenses and pelvic autonomic nervous system where injury or interference to these structures are the potential risks. Extra anal anastomosis of the ganglionated proximal colon to the distal rectal $(\max 2 \mathrm{~cm})$ remnant is done from perineal approach ${ }^{4}$.

Soave endorectal pull through also uses the same combined abdomino-perineal approach as that of Swenson's procedure. It does not involve any extrarectal deep pelvic dissection, and if carried out properly, bears no risk of injuring pelvic structures. Here, the dissection and excision is restricted only to 
the aganglionic mucosal segment from inside the rectum along the submucosal plane. So that $5-7 \mathrm{~cm}$ of aganglionic rectal muscular cuff is left intact through which the distal ganglionated colon is pulled out. Ganglionated colon is anastomosed to rectal mucosa from same perineal approach as in Swenson's procedure ${ }^{4}$.

Both Swenson's and Soave's procedure leave behind laparotomy wounds to heal with every possibility of complications related to them.

Transanal EndoRectal Pull Through (TERPT) is a minimally invasive technical modification of Soave (Endorectal) pull through operation where entire mucosectomy procedure is done through perineal approach without laparotomy or laparoscopy. About 15 centimeter of mucosal tube from the rectosigmoid region can be prolapsed through the anus without laparoscopy ${ }^{5}$. so, it is suitable for the operative treatment of many cases of recto-sigmoid HD. It leaves a 3 to $4 \mathrm{~cm}$ muscular cuff, whereas the original operation (Soave) leaves 5 to $7 \mathrm{~cm}$ muscular cuff 6 . Like Soave operation, TERPT does not interfere with the pelvic nerves and viscera.

To show the per-operative advantages of TERPT over Swenson's pull through operation, we are describing our comparative experience of these two procedures in terms of operative duration, blood loss and transfusion requirement.

\section{Materials and Methods}

It was a prospective study conducted at Dhaka Shishu Hospital during January 2000 to December 2001.

Total 32 biopsy confirmed rectosigmoid HD patients were selected in such a way that there age, body weight and resected rectosigmoid matched well for this comparative study.

They were divided into two groups: $G r . A\left(n_{a}=16\right)$ under went TERPT and designated as 'Study Group'. Gr B $\left(n_{b}=16\right)$ underwent Swenson's pull through operation and designated as 'Control Group'.

As parameter, operative time was defined and recorded in the following way: for TERPT from application of retracting stitches to their removal after colo-rectal anastomosis and for Swenson's pull through- from abdominal skin incision to its closure after colo-rectal anastomosis.

Operative blood loss was estimated by counting blood soaked gauzes (one soaked gauze $=10 \mathrm{ml}$ ) and measuring the collection of blood in the sucker bottle.

For easy comparison volume of operative blood loss was expressed as percentage (\%) of total blood volume (TBV) of the patient; whereas the total blood volume was calculated from body weight of the patient ${ }^{7}$ as for body weight upto $10 \mathrm{~kg} 80 \mathrm{ml} / \mathrm{kg}$ and body weight 10 $30 \mathrm{~kg}$ it is $75.4 \mathrm{ml} / \mathrm{kg}$.

Requirement of blood transfusion was fixed at a point where operative blood loss exceeded $10 \%$ of total blood volume of the patient.

For quantitative data unpaired 't' test and for qualitative parameters $\chi^{2}$ test were done to find any statistical significant.

Unpaired 't' test was used to show that statistically Gr. A and Gr. B matched well and that there was no significant difference $(P>0.05)$ between them with respect to age, body weight and resected rectosigmoid lengths which could influence the study parameters. The same test was also applied for statistical analysis with respect to two quantitative study parameters (operative duration and blood loss) which show significant difference between the two groups to fulfill the study purpose.

$\chi^{2}$ test was used for statistical analysis of the observed results with the other qualitative study parameter i.e. Operative Blood transfusion requirement.

\section{Result:}

The base line parameters including age, weight and resected rectosigmoid length are same $(P>0.015$ in all three variables) in group A and Group B (Table-I).

Required mean operative time for pull through of the patients in Group- A and Group- B were 141.56 minutes and 191.87 minutes respectively. There was significant difference $(P<0.01)$ between 2 groups with lesser time for TERPT (Table - II).

Operative blood loss for pull through. of the patients in Group- A and Group- B ranged from 2.5\% to $21.39 \%$ of total blood volume and from $21.85 \%$ to $26.52 \%$ of total blood volume respectively, which was very highly significant $(\mathrm{P}<0.001)$.

Nine (56.25\%) patients required operative blood transfusion in Group- A, as their operative blood loss exceeded $10 \%$ of their total blood volume (TBV); whereas in Group- B, all the patients required operative blood transfusion for the same reason (Table-III). 
Table-I

Baseline characteristics

\begin{tabular}{lccl}
\hline Characteristics & $\begin{array}{c}\text { Group } \mathrm{A}(\mathrm{n}=16) \\
\text { range }(\text { mean })\end{array}$ & $\begin{array}{c}\text { Group B }(\mathrm{n}=16) \\
\text { range (maen) }\end{array}$ & $\mathrm{p}$ value* \\
\hline Age (months) & $6-31(20.7)$ & $12-32(20.9)$ & $>0.05^{\mathrm{ns}}$ \\
Weight $(\mathrm{kg})$ & $7.2-16(10.4)$ & $913(10.5)$ & $>0.05^{\mathrm{ns}}$ \\
Resected rectosigmid length $(\mathrm{cm})$ & $9.5-14.5(12.3)$ & $10-15(12.5)$ & $>0.05^{\mathrm{ns}}$ \\
\hline
\end{tabular}

* = unpaired ' $\mathrm{t}$ ' test

ns $=$ non significant

Table-II

Operative time for pull through of two groups of patients

\begin{tabular}{lccc}
\hline Operative time & Group A & Group B & ' $p$ 'value for \\
& $\left(\mathrm{n}_{\mathrm{a}}=16\right)$ & $\left(\mathrm{n}_{\mathrm{b}}=16\right)$ & Unpaired 't' test \\
\hline Range (minutes) & $125-175$ & $162-285$ & $<0.01^{\star *}$ \\
Mean (minutes) & 141.56 & 191.87 & \\
\hline
\end{tabular}

** = Highly significant

Table-III

Operative blood loss for pull through of two groups of patients

\begin{tabular}{lccc}
\hline Operative Blood loss & Group A & Group B & 'p' value for \\
& $\left(\mathrm{n}_{\mathrm{a}}=16\right)$ & $\left(\mathrm{n}_{\mathrm{b}}=16\right)$ & Unpaired 't' test \\
\hline Range (TBV\%) & $2.5-21.4$ & $21.9-26.5$ & $<0.001^{\star \star *}$ \\
Mean (TBV\%) & 9.5 & 23.8 & \\
\hline
\end{tabular}

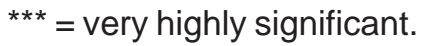

Table-IV

Operative blood transfusion requirement in two groups of patients

\begin{tabular}{|c|c|c|c|c|}
\hline Groups & $\begin{array}{c}\text { Transfusion } \\
\text { required } \\
\text { n (\%) }\end{array}$ & $\begin{array}{c}\text { Transfusion } \\
\text { NOT required } \\
\text { n (\%) }\end{array}$ & $\begin{array}{c}\text { Total number } \\
\text { of patients } \\
n\end{array}$ & 'p'value* \\
\hline$\overline{\text { Gr. A }}$ & $9(56.3)$ & $7(43.8)$ & 16 & $<0.001^{\star \star \star}$ \\
\hline Gr. B & 16 & 0 & 16 & \\
\hline
\end{tabular}

$*=\chi^{2}$ test

$\star \star \star$ very highly significant

\section{Discussion}

There are many advantages of minimally invasive operative techniques like transanal endo rectal pull through over the Swenson's pull through (an open operation).

Operative time requirement for pull through between Group A and Group B patients of our series showed highly significant difference $(P<0.01)$ with lesser time requirement for TERPT than Swenson's pull through.

In our series the maximum operative time required for Swenson's pull through in one patient was 285 minutes, because the surgeon deviated from the plane of dissection during the operation which is not unlikely. 
Three separate American studies showed that the operative time required for TERPT in their series from 95 to $185 \mathrm{~min}^{5}, 135 \mathrm{~min}$ to $210 \mathrm{~min}^{8}$, and $70 \mathrm{~min}$ to $135 \mathrm{~min}^{6}$, with averages of $105 \mathrm{~min}^{5}, 180 \mathrm{~min}^{8}, 110$ $\min ^{6}$ respectively.

An independent Mexican study showed that the same operative time required for TERPT ranged from $90 \mathrm{~min}$ to $300 \mathrm{~min}$ with an average of $186 \mathrm{~min}^{9}$.

Variation in the operative time for TERPT, in our series, was probably due to difference in the development of surgical expertise of the team, while they were on their learning curve.

Operative blood loss for pull through between Group A and Group B patients of our series showed very highly significant difference $(P<0.001)$.

implying lesser operative blood loss for pull through in TERPT.

A Mexican study ${ }^{9}$, in 10 patients of TERPT showed that the operative Blood loss ranged from $0.5 \%$ to $19 \%$ of TBV with an average loss of $8 \%$ of TBV. It conforms well to our study series. Lack of technical expertise may be responsible for the greater blood loss in the earlier patients of our TERPT study series.

Very highly significant difference $(P<0.001)$ between the two groups with respect to operative blood transfusion was observed in this study it also conforms to the former Mexican study ${ }^{9}$.

Significantly higher operative blood loss in Gr. B was likely due to an extra laparotomy wound as well as extensive intrapelvic dissection for Swenson's pull through operation, whereas in $\mathrm{Gr}$. A transanal approach required no laparotomy and only minimum dissection for TERPT. Naturally operative blood loss was significantly lower.

\section{Conclusion}

This limited comparative study with small number of rectosigmoid hirschsprung's disease (HD) patients revalidated the per- operative advantages of transanal endo rectal pull through (TERPT) over Swenson's pull through in terms of operative time, blood loss and transfusion requirement but more studies with large number of HD patients are needed for its further evaluation. The surgeons performing TERPT must be flexible to convert the procedure to an open abdominoperineal operation whenever it is indicated (excessive uncontrolled bleeding, excessive colonic adhesion, etc). Follow up studies will be required to evaluate the operative success of TERPT in terms of preservation of bowel function and post-operative morbidities.

\section{References}

1. Hutson JM, Beasley SW, Woodward AA, editors. Jones' Clinical Pediatric Surgery Diagnosis and management. Melbourne: Blackwell Scientific Publications, 1992.

2. Leape LL. Patient care in pediatric surgery. $1^{\text {st }}$ ed. Boston: Little Brown and Company 1987.

3. Shankar KR, Losty PD, Lamont GL. Transanal Endorectal coloanal Surgery for Hirschsprung's disease: experience two centers. J Pediatr Surg 2000; 35: 1209-13.

4. Alexander $\mathrm{H}$, Beno MU. Hirschsprung's Disease. In: Keith WA, Partic M, Ronald JS, David LS, Charles LS, editors. Pediatric Surgery. $3^{\text {rd }}$ ed. Philadelphia: WB Saunders Company; P 2000. P. 462-64.

5. Albanese CT, Jennings RW, Smith B. Perineal one-stage Pull-Through for Hirschsprung's disease. J Pediatr Surg.1999; 34: 377-80.

6. Saltzman DA, Telander MJ, Brennom WS. Transanal Mucosectomy A modification of the Soave Procedure for Hirschsprung's disease. J Pediatr Surg 1996; 31: 1272-75.

7. Hutchison RJ. Surgical implications of hematologic disease, Peadratr Surg. $5^{\text {th }}$ ed.1998;166.

8. Langer JC, Seifert M, Minkes RK. One-Stage Soave Pull-Through for Hirschsprung's disease. J Pediatr Surg 2000; 35: 820-22.

9. De la Torre L, Ortega A. Transanal Versus Open Endorectal Pull-Through for Hirschsprung's disease J Pediatr Surg. 2000; 35: 1630-32. 